\title{
Novos horizontes que ressignificam a doença renal crônica por meio da arteterapia e
}

\section{do recurso autobiográfico}

\author{
New horizons on signifying chronic kidney disease with art therapy and autobiography \\ Nuevos horizontes que re-significan enfermedad renal crónica mediante artoterapia y recursos \\ autobiográficos
}

Recebido: 14/02/2021 | Revisado: 27/02/2021 | Aceito: 03/03/2021 | Publicado: 08/03/2021

\author{
Felipe Santos da Silva \\ ORCID: https://orcid.org/0000-0002-1409-4832 \\ Universidade Estadual de Campinas, Brasil \\ E-mail: felipe.stos.sva@gmail.com \\ Liandra Aparecida Orlando Caetano \\ ORCID: https://orcid.org/0000-0003-1898-889X \\ Universidade de São Paulo, Brasil \\ E-mail: liandraorlando@outlook.com \\ Joice Nayara dos Santos \\ ORCID: https://orcid.org/0000-0002-5949-9024 \\ Universidade de Franca, Brasil \\ E-mail: joice.nayara14@gmail.com \\ Carina Faleiros Ribeiro Lopes \\ ORCID: https://orcid.org/0000-0003-3626-6102 \\ Universidade de Franca, Brasil \\ E-mail: carina.faleiros@yahoo.com.br \\ Fabiana Spirlandeli Domenice \\ ORCID: https://orcid.org/0000-0002-2195-9216 \\ Universidade de Franca, Brasil \\ E-mail: fabispirlandeli@hotmail.com \\ Ligia Peres Tozati \\ ORCID: https://orcid.org/0000-0002-5213-863X \\ Universidade de Franca, Brasil \\ E-mail: Iptozati@gmail.com
}

\section{Resumo}

O objetivo desse trabalho foi promover simultaneamente as habilidades de vida e qualidade de vida para pacientes em hemodiálise, oferecendo-lhes um espaço de escuta e bem-estar social, frente à condição de Insuficiência Renal Crônica (IRC) através de intervenções psicológicas e da arteterapia que funcionaram como ferramentas para (re)pensar os cuidados relacionados à saúde mental. O presente estudo de natureza qualitativa, foi realizado de março à junho de 2019, e buscou os nexos de sentido atribuídos nos relatos durante a confecção dos livros autobiográficos. Tratou-se de uma pesquisa de campo aprovada pelo CEP, conforme consta no CAEE: 12389219.5.0000.5495, em que cerca de noventa pacientes em hemodiálise, de uma clínica nefrológica foram convidados a participar da pesquisa. O projeto denominado "Biografia", viabilizou compilar fragmentos das histórias de vida dos participantes, e assim, oferecer subsídios para (re)significar, os conceitos de saúde e doença, a luz da teoria das Habilidades de Vida e da Psicologia da Saúde. Os materiais e técnicas utilizadas foram: intervenções psicológicas (escuta ativa, acolhimento e reflexões) entrevistas semidirigidas abertas em profundidade, roteiro semiestruturado, observação, transcrições, diários de campo, e o uso de materiais gráficos para arteterapia manuseados pelos participantes para confecção das capas dos livros. Os resultados evidenciaram a eficácia das intervenções psicológicas privilegiando as habilidades de vida e o uso da arteterapia que dão destaque as habilidades que pessoas com insuficiência renal possuem. A produção coletiva do material autobiográfico pôde além de promover saúde mental, favorecer a melhora na qualidade de vida através do resgate da identidade dos participantes.

Palavras-chave: Insuficiência renal crônica; Sistemas de apoio psicológico; Terapia pela arte; Habilidades para a vida; Promoção de saúde.

\footnotetext{
Abstract

The objective of this study is to promote both life and health quality to hemodialysis patients, thus offering them a safe sharing space and a social safe environment, due to their Chronic Kidney Failure condition. To achieve this paper'a objective, the researches promoted psychological interventions and sessions of art therapy. Both tools worked
} 
as ways to ponder about mental health. The study was carried from March to June of 2019, and tried to unveil the meaningful links between the patients' interviews and their composition of autobiographical books. The methodological approach of this study may be described as qualitative, its development was based in a field research. The reassert was approved by the Brazilian Ethics and Research Committee (Comitê de Ética e Pesquisa - CEP) under the following number CAEE 12389219.5.0000.5495. A number of 90 patients in Chronic Kidney Failure, of a Brazilian clinic, were invited to take part on the research. The psychological intervention produced a project called "biografia" in which the participants composed an autobiographical book of their life stories. The project was used to promote ways for the participants to think about the concepts of health and disease in their lives and to signify those concepts through Life Skills and Health Psychology. The materials and techniques of this study may be described as psychological interventions (active listening, welcoming and reflections) semi-structured interviews opened in depth, semi-structured script, observation, transcriptions, field diaries, and the use of graphic materials for art therapy handled by the participants to make the covers of the participants books. The results show the efficiency of psychological interventions based on arts and how such interventions may promote health and life quality to the participants when it comes to redeem their identity.

Keywords: Chronicle kidney disease; Psychological support systems; Art therapy; Life skills; Health promotion.

\section{Resumen}

El objetivo de este trabajo fue promover simultáneamente las habilidades y la calidad de vida de los pacientes en hemodiálisis, ofreciéndoles un espacio de escucha y bienestar social, ante la condición de Insuficiencia Renal Crónica (IRC) a través de intervenciones psicológicas y de la arteterapia que funcionaron como herramientas para (re) pensar la atención relacionada con la salud mental. El presente estúdio cualitativo se llevó a cabo de marzo a junio de 2019 , y buscó los nexos de significado atribuidos en los informes durante la confección de libros autobiográficos. Se trató de un estudio de campo aprobado por el CEP, según consta en el CAEE: 12389219.5.0000.5495 en el que se invitó a participar en la investigación a unos noventa pacientes en hemodiálisis de una clínica de nefrología. El proyecto denominado "Biografía", permitió recopilar fragmentos de las historias de vida de los participantes, y así ofrecer subsidios para (re) significar, los conceptos de salud y enfermedad, a la luz de la teoría de Habilidades para la Vida y Psicología de la Salud. Los materiales y técnicas utilizadas fueron: intervenciones psicológicas (escucha activa, acogida y reflexiones) entrevistas semiestructuradas abiertas en profundidad, guión semiestructurado, observación, transcripciones, diarios de campo, y el uso de materiales gráficos para arteterapia manejados por los participantes para hacer las cubiertas del libro. Los resultados mostraron la efectividad de las intervenciones psicológicas que privilegian las habilidades para la vida y el uso de la arteterapia que resaltan las habilidades que tienen las personas con insuficiencia renal. La producción colectiva de material autobiográfico podría, además de promover la salud mental, favorecer la mejora de la calidad de vida mediante del rescate de la identidad de los participantes.

Palabras clave: Insuficiencia renal crónica; Sistemas de apoyo psicologico; Terapia con arte; Habilidades para la vida; Promoción de la salud.

\section{Introdução}

A Insuficiência Renal Crônica (IRC) é uma condição que além de provocar transformações físicas na vida do indivíduo que a vivencia, concebe prejuízos psicológicos alterando o seu cotidiano. Trata-se de um problema social, que interfere no papel que esse indivíduo desempenha na sociedade e em suas relações subjetivas e com os demais. Essa realidade, por vezes, demanda um longo processo de adaptação a essa condição, sob a qual, o indivíduo precisa identificar meios para lidar com o problema e com todas as mudanças e limitações que dele decorrem.

A doença renal crônica (DRC) é uma síndrome clínica secundária à alteração definitiva da função e / ou estrutura do rim e é caracterizada por sua irreversibilidade e evolução lenta e progressiva. Outro aspecto importante é que a patologia representa maior risco de complicações e mortalidade, principalmente as cardiovasculares (Ammirati, 2020, p. 53).

A IRC entendida como essa situação limitadora coloca o indivíduo fadado a viver uma realidade que ele não imaginava. Comumente a pessoa diagnosticada com IRC não aceita sua condição, o que desencadeia inúmeras experiências emocionais negativas afetando, sobretudo, a sua qualidade de vida.

Segundo a literatura científica e um dos inúmeros instrumentos que mensuram os aspectos físicos, psicológicos, sociais e espirituais da qualidade de vida que são influenciados pela saúde e eventos relacionados à saúde, como doenças e 
seus tratamentos (Ferrans et al., 2005; Karimi \& Brazier, 2016), está bem documentado que estágios avançados de doença renal crônica (DRC) (ou seja, 4 e 5) juntamente com diálise (ou seja, hemodiálise ou diálise peritoneal) impactam negativamente na qualidade de vida relacionada à saúde (QVRS) de pessoas que têm DRC (Picariello et al., 2016; Ju et al., 2018).

Os impactos psicológicos da IRC na vida do indivíduo apontam situações em que grande parte das pessoas, após o diagnóstico de IRC, sinta desconforto, angústia, impotência, e com isso, quadros depressivos e ansiosos entre tantos outros possam se instalar sobre suas vidas, demandando apoio e cuidados psicológicos.

Nesse sentido é de suma importância destacar o papel da Psicologia que atua junto ao serviço de hemodiálise, visto que esta deve auxiliar no enfrentamento da doença, propiciando o resgate da essência de cada paciente, cabendo também ao psicólogo, inicialmente entender o que está envolvido nas queixas, através da escuta ativa, oferecendo suporte ao paciente, sua família e toda a equipe de saúde.

É importante que outros caminhos possam ser pensados e novas práticas sejam adotadas, em conjunto ao apoio psicológico, de maneira que o paciente renal crônico seja assistido e compreendido integralmente. A arteterapia atua como recurso para lidar com estas situações, e o psicólogo por sua vez, passa a atuar como mediador deste processo de enfrentamento.

Arteterapia é uma área de atuação profissional que utiliza recursos artísticos com finalidade terapêutica (Carvalho, 1995). Na definição da Associação Brasileira de Arteterapia ${ }^{1}$, "é um modo de trabalhar utilizando a linguagem artística como base da comunicação clienteprofissional. Sua essência é a criação estética e a elaboração artística em prol da saúde" (Reis, 2014, p. 143).

Frente à problemática das demandas psicológicos adjacentes da condição renal crônica, a necessidade do olhar humanizado e mais do que isso, de serem disseminadas práticas assertivas que possuem por finalidade alcançar pessoas acometidas por diversas patologias e que se veem reféns da dependência de hospitais, centros de saúde e outros meios em que se buscam atendimentos na ânsia de tratamentos que viabilizam a melhoria ou cura de tais enfermidades que os acometem, aponta para o surgimento de novas formas de intervir e tratar o conceito "saúde" e "doença" sob novos olhares e novas perspectivas, e a Arteterapia auxilia nesse sentido, (re)ssignificando a doença.

Jung (1875-1961), ilustre discípulo de Freud, com quem posteriormente rompeu ao desenvolver sua própria teoria, a Psicologia analítica, foi quem propriamente começou a usar a linguagem artística associada à psicoterapia. Diferentemente de Freud, que considerava a arte uma forma de sublimação das pulsões, Jung considerava a criatividade artística uma função psíquica natural e estruturante, cuja capacidade de cura estava em dar forma, em transformar conteúdos inconscientes em imagens simbólicas (Silveira, 2001) (Reis, 2014, p. 145).

Outro ponto que merece destaque refere-se às Habilidades de vida preconizadas pela Organização Mundial de Saúde (OMS), que são: autoconhecimento, empatia, comunicação eficaz, relacionamentos interpessoais, tomada de decisões, resolução de problemas, pensamento criativo, pensamento crítico, manejo de sentimentos e emoções, e o manejo do estresse. O desenvolvimento de tais competências, frente ao processo de adoecimento sob o qual o paciente está imerso pode favorecer o enfrentamento da doença.

A OMS (1997) sugere que o modelo de habilidades de vida consiste em favorecer o desenvolvimento de um conjunto de dez competências, sendo agrupadas em categorias que se complementam: habilidades sociais e interpessoais, habilidades cognitivas e habilidades para manejar as emoções (Paiva \& Rodrigues, 2008, p. 677). 
O objetivo desse trabalho foi promover simultaneamente as habilidades de vida e qualidade de vida para pacientes em hemodiálise, oferecendo-lhes um espaço de escuta e bem-estar social, frente à condição de Insuficiência Renal Crônica (IRC) através de intervenções psicológicas e da arteterapia que funcionaram como ferramentas para (re)pensar os cuidados relacionados à saúde mental.

\section{Metodologia}

O presente trabalho refere-se à realização de uma pesquisa em que os alunos do curso de Psicologia, graduandos do quinto ano realizaram, a partir de um estágio curricular em Psicologia da Saúde, em uma clínica nefrológica do interior do estado de São Paulo.

A mensagem central da psicologia da saúde, obviamente, é que a saúde e a doença estão sujeitas a influências psicológicas. Por exemplo, um fator fundamental para determinar o quanto uma pessoa consegue lidar com uma experiência de vida estressante é a forma como o evento é avaliado e interpretado. Eventos avaliados como avassaladores, invasivos e fora do controle custam mais do ponto de vista físico e psicológico do que os que são encarados como desafios menores, temporários e superáveis. (Straub, 2014, p. 15, grifos nossos).

Trata-se de uma pesquisa de natureza qualitativa (Minayo, 2007), que viabilizou buscar os nexos de sentido presentes nos relatos dos participantes do estudo. Foi aprovada pelo CEP conforme consta no CAEE: 12389219.5.0000.549.

A pesquisa qualitativa tem como objetivo investigar de maneira aprofundada os fenômenos, emergentes em determinado contexto, e analisa-los à luz de determinada teoria. Em nosso caso, utilizamos a Psicologia da Saúde, as Habilidades de vida e a Arte Terapia.

Segundo Pereira et al., podemos definir que:

Os métodos qualitativos são aqueles nos quais é importante a interpretação por parte do pesquisador com suas opiniões sobre o fenômeno em estudo. Neles a coleta de dados muitas vezes ocorre por meio de entrevistas com questões abertas. Neste tipo de pesquisa algumas características, conforme Ludke e Andre (2013), são: 1) A pesquisa qualitativa, em geral, ocorre no ambiente natural com coleta direta de dados e o pesquisador é o principal instrumento; 2) Os dados coletados são preferencialmente descritivos; 3) A preocupação do processo é predominante em relação à do produto; 4) O "significado" que as pessoas dão as coisas e a sua vida são focos de atenção para o pesquisador e, 5) A análise de dados e informações tende a seguir um processo indutivo (Pereira et al., 2018, p. 67).

Nesse sentido, nos norteamos pelas etapas apresentadas acima, para a aplicabilidade do método qualitativo no contexto da saúde.

Os participantes foram pacientes que eram submetidos ao tratamento de insuficiência renal crônica através da hemodiálise e aceitaram participar da pesquisa.

Os critérios de inclusão utilizados foram: todos os pacientes que estavam recebendo o tratamento de hemodiálise regularmente na clínica; podendo ser do sexo masculino ou feminino, sem limites de idade, desde que fossem maiores de 18 anos, e que tivessem aceitado o convite em participar das intervenções apresentadas inicialmente e da confecção do livro, e acordado com o Termo de Consentimento Livre e esclarecido. A amostra foi fechada por exaustão, ou seja, foram incluídos todos os participantes que cumpriam os critérios de inclusão para o estudo, totalizando uma média de 90 participantes.

Os instrumentos e técnicas utilizadas foram: intervenções psicológicas, a observação participante, transcrição dos dados (no momento das entrevistas, feitas sempre, por um dos pesquisadores), diários de campo, entrevistas semidirigidas abertas em profundidade, roteiro de entrevista semiestruturado e o uso dos materiais de arte para a confecção dos livros. 
Tratou-se de um estudo conduzido por um grupo de seis pesquisadores, que tiveram o apoio da psicóloga, dos médicos (as) de plantão na clínica e dos enfermeiros que auxiliavam aos pacientes durante os procedimentos de hemodiálise. A coleta dos dados ocorreu durante o período de 14/03 a 15/06 de 2019.

Cada encontro teve duração média de 03h00min horas à 03h30min horas, ou seja, ocorreram durante as sessões de hemodiálise, semanalmente. No entanto, cada entrevista individual com os participantes, teve a duração em média de 20 a 30 minutos, e aconteceram duas vezes por semana na clínica, com a presença dos pesquisadores, junto aos pacientes com insuficiência renal crônica e a equipe multiprofissional. Os indivíduos atendidos foram bastante heterogêneos, variando de idade (fase adulta acima de 18 anos até a terceira idade 96 anos), sexo (masculino e feminino), e período de tratamento (de um mês até quinze anos).

Nos encontros iniciais os pesquisadores dividiram os pacientes em pequenos grupos (compostos de três e quatro participantes), visto que a demanda era grande e devido às questões logísticas de espaço, ficaria inviável a criação de um só grupo para tratar as particularidades de cada um. Os pesquisadores se apresentaram formalmente aos grupos, e em seguida solicitaram aos pacientes/profissionais que respondessem as questões que iriam compor os conteúdos dos livros.

Foram confeccionados livros contendo as histórias de vida dos pacientes/funcionários, e posteriormente, ocorreu o lançamento da obra e a distribuição para todos os envolvidos.

A elaboração dos livros contou ainda com oficinas de arteterapia em que os participantes puderam realizar a criação da capa e contracapa individual, se utilizando de materiais gráficos como cola, tinta, papel colorido, lã, algodão e outros materiais. Esse processo viabilizou trabalhar as potencialidades de cada um e evidenciou a possibilidade de desenvolvimento de trabalhos manuais, respeitando a situação na qual os pacientes se encontravam, resgatando a capacidade de desenvolvimento do pensamento criativo, uma das habilidades, descritas no manual das habilidades de vida.

A análise de conteúdo realizada seguiu três etapas: apreciação e discussão dos relatos coletados após cada encontro, a discussão dos dados coletados após a supervisão com a pesquisadora responsável, e por fim, o tratamento e interpretação dos resultados obtidos, que conceberam as categoriais de análise, a luz da Psicologia da Saúde, que foram: 1. Uma nova realidade: a mudança, a frustração, os medos e a adaptação; 2. O pensamento criativo e o resgate do elo perdido; 3. A emergência do cuidado com a saúde mental; 4 . A vontade de ter vontade e de viver o porvir; $\mathbf{5}$. A fé como forma de enfrentamento da doença; 6. Revisitando e redesenhando a imagem de si através da autobiografia.

Abaixo serão apresentados apenas recortes de depoimentos de parte dos participantes da pesquisa, devido ao grande volume de dados coletados. Subsequentemente os demais relatos serão distribuídos e apresentados em novos artigos.

\section{Resultados e Discussão}

Durante a primeira visita no local onde a pesquisa foi realizada, os pesquisadores puderam observar por meio do contato com os pacientes renais e das informações destacadas pela psicóloga da instituição, que a demanda emergente referiase à baixa autoestima, sentimento de impotência, tristezas, angústias e dificuldades que os pacientes apontam após os diagnósticos de insuficiência renal; depressão; cegueira; diabetes e hepatite.

$\mathrm{O}$ adoecimento físico e psicológico constitui um desequilíbrio ou desordem que nem sempre possui uma causalidade que o justifique, e quando isso ocorre, na maioria das vezes as pessoas ao descobrirem que possuem determinadas doenças, mergulham em um processo de questionamento interno que as coloca em crise consigo mesmas e com os demais. Ocorre que na maioria das vezes, a doença se apresenta por meio de sintomas, quase sempre, ignorados pelo indivíduo, e quando ele se dá conta, está imerso em um quadro patológico que demanda atenção, cuidado e a adoção de novos hábitos e significados para a sua vida. 
Segundo Fontora (2012) podemos caracterizar a insuficiência renal como:

A doença renal crônica (DRC), também conhecida como insuficiência renal crônica, consiste no comprometimento lento, insidioso e irreversível da função renal. Isso ocorre em decorrência do excesso de produtos hidrogenados (ureia e creatinina) no sangue, os quais impossibilitam os rins de manterem o equilíbrio corporal. As patologias renais podem comprometer o órgão de maneira rápida ou gradativamente, neste o portador pode se manter assintomático por anos, o que dificulta o diagnóstico precoce (Fountora apud Santos, 2018, p. 163).

Analisando a definição acima podemos empreender nessa reflexão, a constatação de uma doença que por ser irreversível afeta quem a possui de maneira significativa e para o seu diagnóstico e a posteriori, faz-se necessário o manejo para explicitar a existência e futuro do indivíduo do qual a doença se revela. Além disso, ocorre o surgimento de várias outras problemáticas, nos casos em que não há o diagnóstico prévio da falha renal em casos assintomáticos.

O contato com o paciente, o entendimento do processo de adoecimento, bem como uma relação de proximidade possibilita um canal de escuta, conforme citado por Botega (2017), o paciente acometido por doença crônica necessita estabelecer um vínculo forte, para isso cabe ao profissional identificar, compreender e contextualizar dentro da história de vida relatada os sentimentos despertados pelo paciente, tais como: frustração, medo, raiva. O psicólogo que se coloca de forma compreensiva, empática e simples, permite uma aproximação com maiores chances de serem assertivas e efetivas.

O oferecimento de uma escuta ativa, como destaca Botega (2017), que se expressa por um ouvir com disponibilidade de tempo, bem como com uma postura de quem procura conhecer sem crítica e sem julgamento, proporciona um ambiente físico de acolhimento, respeito e interesse pelo paciente. Estabeleceu-se assim uma conversa com perguntas gerais, descontraídas propiciando uma proximidade interpessoal adequada aos pacientes.

É importante, contudo, que o psicólogo realize uma práxis, onde não seja individualizante ou psicologizante de fatores sociais, além do que realizar essa escuta e trabalho realizado permite que compreendamos o sujeito como produto e produtor de seu meio, sendo que cada um possui sua história, família e lugar no mundo. Assim consegue-se por meio dessas ações, promover autonomia, conscientização, visando à transformação do social (Cintra \& Bernardo, 2017).

Apresentaremos abaixo alguns recortes dos depoimentos dos participantes da pesquisa, analisados à luz do arcabouço teórico das Habilidades para a vida (Castellanos \& Pizón, 2017) e da Psicologia da Saúde (Angerami, 2002).

Nos primeiros contatos com os pacientes, foi percebido que houve uma necessidade de falar sobre acontecimentos do passado, infância e ao perguntar sobre o que gostavam de fazer deram destaque às limitações, ocasionadas pelo tratamento, alegando que deixaram de fazer o que gostavam, como quando um dos participantes disse: "Amava fazer qualquer serviço" (Informante 1).

A proposta foi então, estabelecer um vínculo por meio de conversa baseada em duas perguntas iniciais, presentes no roteiro semiestruturado: "O que você gosta de fazer?" e "O que você gostaria de colocar no livro, para que outras pessoas lessem em relação ao enfrentamento ao tratamento?", para o momento da atividade da construção coletiva do projeto biografia.

Em muitas falas surgidas após essa pergunta, é possível entender que alguns fatores, como a rede de apoio social (familiares, amigos) são ajudas essenciais no tratamento, sendo esse fator, por exemplo, uma contribuição positiva no enfrentamento da doença e tratamento, assim como uma influência pessoal (Gomes et al., 2018).

Além disso, outro aspecto percebido foi a importância do apoio multidisciplinar oferecido pela instituição, relacionada aos cuidados necessários aos pacientes que os motivam a continuar na manutenção pela vida, uma vez que eles passam grande parte do tempo na clínica, e devido ao acolhimento recebido, sentem-se em casa. É importante que eles se 
sintam amparados e acolhidos, sendo um tratamento longo e traumático exige uma equipe multidisciplinar, profissionais que saibam ouvir o paciente e possa explicar o que for necessário (Freitas \& Cosmos, 2010).

\section{Uma nova realidade: a mudança, a frustração, os medos e a adaptação}

Foi percebido, que muitos participantes deram significados e se adaptaram a nova forma de viver, após o diagnóstico da doença. Eles destacaram aspectos positivos relacionados ao enfrentamento da doença, e sobre a nova forma de ver a vida, ressignificando a importância de priorizar coisas do cotidiano, como tomar um café com os amigos, poder conversar com as pessoas, e até mesmo, pensar sobre a importância do conhecimento para fazer projeções para o futuro.

Essa adaptação só se torna possível com a conscientização do paciente sobre sua doença e a necessidade de tratamento permanente (...). A tranquilidade e o bom estado emocional do paciente aparecem, então, como condições essenciais, não só para a manutenção de seu tratamento, mas também para o prolongamento de sua existência, ampliando as possibilidades de melhora da sua qualidade de vida (Angerami, 2012, p. 148).

Alguns pacientes, inicialmente, se recusaram em participar do projeto biografia. Uma hipótese que justifica tal recusa refere-se à própria dificuldade/negação em falar sobre o adoecer. Pois quando a pessoa adoece "sente-se ameaçada e muitos sentimentos são sentidos e vivenciados" (Angerami, 2012). Porém, após alguns encontros que os pesquisadores estiveram presentes, esses pacientes voltaram atrás e decidiram participar, e falaram sobre aspectos de suas vidas que causavam desconforto. Nesse sentido, entende-se que, por meio da própria fala é possível construir sentidos acerca de nós mesmos, das pessoas e do mundo que vivemos (Martínez, 2014).

Existem ainda àqueles pacientes que não aceitam bem o tratamento, por relatarem ser ruim, no entanto, o percebem como necessário. Esse aspecto foi percebido tanto em pacientes que estão em tratamento há um tempo, e também naqueles que iniciaram recentemente. "A hemodiálise acarreta sentimentos ambíguos de aceitação e revolta nos sujeitos que necessitam deste tratamento para sobreviver, pois ao mesmo tempo em que garante a vida, torna a pessoa dependente da tecnologia" (Silva et al., 2011, p. 841).

Segundo dados de outro estudo realizado com pacientes renais crônicos, em que pesquisadores investigaram os fatores psicossociais prevalentes nestes, é possível observar a ocorrência de sentimentos e emoções disfóricas frente ao adoecimento, às mudanças que dele decorrem e a dificuldade de encontrar apoio e amparo para lidar com os inúmeros conflitos internos e externos que o paciente enfrenta ao descobrir a IRC, o que demanda manejo específico na busca de auxiliar esse indivíduo.

O impacto da descoberta da doença e adesão ao tratamento geram repercussões psicológicas negativas, trazendo sentimentos como, medo, tristeza e desejo de morrer. Desse modo, torna-se perceptível a importância de um acompanhamento psicológico, fortalecendo o tratamento junto aos demais profissionais envolvidos (Rodrigues; Silva \& Barbosa, 2020, p.15).

Quando houve o início a confecção das capas dos livros foi fundamental que a psicóloga e os demais profissionais incentivassem aos pacientes a desenvolverem suas capacidades, propiciando a abertura para a interação entre eles, além de promover o bem estar conjunto (Freitas \& Cosmos, 2010).

\section{$O$ pensamento criativo e o resgate do elo perdido}

A maioria dos participantes demonstrou certo receio ao iniciar a confecção, porém, mesmo assim decidiram se arriscar e tentar. Alguns pacientes relataram que fazia muito tempo que não produziam desenhos, e alguns se preocuparam em 
ser fidedignos às imagens de si, demonstrando que conheciam bem as suas características, gostos e desgostos, valores e atitudes que fazem parte do pensamento criativo (Castellanos; Pizón, 2017). Além disso, ao entrar em contato com a criatividade, relatavam vários aspectos vividos, de enfrentamento a doença usando as emoções, razão e sentimentos para inventar, criar após ver as coisas com perspectivas diferentes das usualmente utilizadas (Castellanos \& Pizón, 2017).

Os recursos artísticos abrem caminho para a comunicação com estes pacientes, pois estabelecer uma comunicação pode ser difícil, devido ao contexto hospitalar e aos procedimentos invasivos. A arte terapia permite o estabelecimento de vínculos com o paciente, e isso leva a exteriorização de conflitos internos e das fantasias que o paciente cria a partir do diagnóstico. Quando o paciente está criando algo, seja um desenho, uma colagem ou qualquer tipo de produção artística é produzido também um processo de elaboração e reflexão (Garcia, 2004).

Ao dar livre curso as expressões das imagens internas, o indivíduo, ao mesmo tempo, em que as modela, transforma a si mesmo. Ao conhecer aspectos próprios se cria, se educa e sobre tudo pode experimentar inserir-se na realidade de uma maneira nova[...] (Andrade, 1993 apud Garcia, 2004, p. 13).

A atuação na mediação neste processo da arteterapia concebeu um efeito terapêutico através das trocas verbais que aconteceram durante a confecção das capas, em que as dificuldades dos pacientes surgiram e a partir desses conteúdos, é possível apresentar uma nova perspectiva para eles, visando o bem-estar e a melhora na percepção de si e dos outros (Yokota, 2004). O que está diretamente ligado à promoção do autoconhecimento e do pensamento criativo que consiste em reconhecer em si mesmos sentimentos, qualidades e defeitos e a partir disso aceitar e dar um novo significado, buscando alternativas para lidar com as situações do nosso cotidiano (Paiva \& Rodrigues, 2008).

Durante a confecção das capas foi possível perceber o quanto a doença traz uma postura passiva, e um sentimento de incapacidade, pois alguns pacientes trouxeram em suas falas, que não conseguiriam fazer, ou direcionavam a confecção à terceiros, pois se viam como incapazes de executar as atividades. Segundo Paula, et al., (2007) no contexto da rotina do tratamento de hemodiálise, os pacientes passam por um processo de despersonalização, deixam de ter autonomia, levando a uma postura passiva e de dependência. Os pesquisadores foram, aos poucos, atribuindo funções a eles, como, escolher as figuras ou fazer alguma parte com lápis de cor, "sendo assim, na proposta lúdica o paciente pode distanciar-se da realidade que está vivendo, exercitar sua autonomia e reconhecimento de si” (Paula, et al., 2017, p. 148). Ressalta-se que o lúdico tem a potencialidade de auxiliar na restauração da confiança em si e no interesse pela vida, reduzindo sentimento de culpa e inutilidade. Após o incentivo dos pesquisadores, e ao observarem o que haviam produzido alguns dos participantes, relataram ter conseguido fazer além do que imaginavam (Santos, 2000 apud Paula et al., 2017, p. 148).

\section{A emergência do cuidado com a saúde mental}

Noutra perspectiva foi necessário fazer algumas intervenções de psicoterapia breve com grande parte dos pacientes, que apontaram a dificuldade em aceitar a condição da doença, e com isso, se encontravam em momentos de crise.

Para exemplificar, uma paciente destacou que se viu paralisada na continuidade de seu processo de vida. Um dos pesquisadores realizou uma intervenção de apoio breve, e reportou a situação para a psicóloga da clínica. É importante apresentar outra perspectiva ao paciente, mostrar a ele o que se pode fazer de bom nesses momentos. Para a realização dessa intervenção breve utilizou-se a sugestão de condutas alternativas (Holanda, 2007).

Nos últimos encontros, os pesquisadores aplicaram uma técnica de relaxamento em um paciente da clínica. Ele relatou estar se sentindo ansioso e não sabia o que fazer para minimizar isso. "Algumas técnicas são voltadas para a promoção do bem-estar físico e psicológico: logo, são mais indicadas para o alívio de sintomas de estresse, de ansiedades, dentre outras. Uma das técnicas desenvolvidas é a de respiração diafragmática" (Marques \& Delfino, 2016, p. 5). 
Foram identificados alguns pacientes que se focavam nos aspectos positivos para enfrentamento da doença. Nesse sentido, era possível observar que o oferecimento de encorajamento e a elevação da autoestima do paciente, pela aprovação e respeito de suas atitudes era ponto central para propiciar o bem estar a eles frente àquela situação (Holanda, 2007). No contexto de saúde vs doença, é importante a atuação do psicólogo de modo que ele possa atuar com uma escuta ativa, e apresentar novas perspectivas para o paciente que iniciar um novo percurso, (re)aprendendo a caminhar "um atendimento mais humanizado, que reconheça a singularidade de cada paciente, compreenda a fragilidade submetida pela doença crônica e que faça emergir - dentro dos recursos pessoais de cada paciente - a capacidade de ressignificação da própria vida" (Freitas \& Cosmos, 2010, p. 31).

\section{A vontade de ter vontade e de viver o porvir}

Foram identificadas, em grande parte dos pacientes, necessidades de falar, contar e remontar momentos de suas histórias de vida pessoal, relações familiares, seus modos de vinculação, suas habilidades e gostos. Em grande parte eles trouxeram as habilidades culinárias, o gosto pela dança, músicas e viagens que realizam frequentemente. Um deles destacou que mesmo diante da limitação da doença, há otimismo e desejo de melhora e progresso, por exemplo: "não consigo mais pintar, mas tenho vontade de ter vontade" (Informante 1).

Outro fragmento refere-se à fala da Informante 2., quando ela menciona "tenho dificuldades de enxergar e dores na coluna, mas ficarei bem, já estou em tratamento".

Já a Informante 3. relata grande necessidade de ser pró ativa em relação às atividades diárias, disse que sempre procura algo para fazer como a participação em grupos de dança em várias cidades da região.

A realização de intervenções grupais aponta um caminho bastante proveitoso no que se refere ao manejo emocional e a própria interação social entre os pacientes que possuem doenças crônicas, e que por consequência delas, diversos fenômenos emocionais começam a emergir. Segundo Silva; Caetano; Silveira e Junqueira (2019, p. 100) observa-se "a eficácia de intervenções terapêuticas em grupo, se tratando da melhora na interação social entre os usuários", quando analisados os resultados de atividades grupais com pacientes institucionalizados que começam a se sentir bem, pela possibilidade de contato com seus pares.

Um caso peculiar que chamou a atenção dos pesquisadores foi do Informante 4. que com 94 anos de idade demonstra lucidez, alegria e descontração, destacou que sempre viaja para visitar o filho em outra cidade.

As formas de enfrentamento coping que influenciam a reação do paciente frente à doença e no seu estado geral, bem como a capacidade de compreensão de todo processo de adoecimento foram identificadas nesse primeiro contato com os pacientes. Falar das limitações traz muitos sofrimentos, mas o desejo pela melhora e o enfrentamento das limitações ficou ainda mais evidente.

As pessoas cujo coping é orientado para a solução de problemas, ao lidarem com situações de doença, tenderão a buscar informações, procurarão trocar ideias com médicos, amigos, grupos de autoajuda, a fim de alterarem suas concepções, seus hábitos e as características do ambiente em que vivem. Tudo isso com a finalidade de reassumirem o controle de suas vidas, tornando as consequências da doença mais toleráveis (Botega, 2017, p. 53).

\section{A fé como forma de enfrentamento da doença}

Outro paciente relatou que gosta muito de ler, tanto em casa como durante o tratamento recebido na clínica, além de destacar que é professor de evangelização em sua igreja, e que tem grande facilidade em se comunicar com os outros, enfatizando: "Me preocupo com o ser humano, principalmente com a alma, tenho a intenção de levar o bem ao próximo" (Informante 5). 
Quando questionado sobre a maneira como ele lida com o tratamento recebido, o Informante 5 conta: "Encarei como algo normal, não como algo difícil, o tratamento vale a pena, é muito diferente do que os outros pensam". Em análise aos fragmentos acima, foi possível identificar que o paciente possui uma visão positiva de sua condição atual, enquanto paciente renal crônico, em tratamento somente há três meses.

É essencial para o sucesso da terapia, profissionais capacitados dispostos a trabalhar em articulação com a equipe multiprofissional, com os pacientes e seus familiares, objetivando minimizar os índices de complicações e aumentando a qualidade de vida dos pacientes em terapia hemodialítica. (Santana et al., 2013, p. 10).

Outro paciente compartilhou como mensagem para ser colocada no livro o seguinte: "Eu passei um problema muito difícil há um ano, mas graças a Deus, hoje eu estou em um período bom” sugeriu ainda, "As pessoas não devem desanimar, devem ter pensamento positivo" (Informante 6).

Essa adaptação só se torna possível com a conscientização do paciente sobre sua doença e a necessidade de tratamento permanente, com modificações na alimentação e nos comportamentos. Para tanto, o paciente necessita de apoio psicológico e de um clima favorável para falar sobre seus medos, referentes à possibilidade de morte, tanto sua quanto a de seus companheiros, de suas perdas físicas e sociais e de seu futuro. A tranquilidade e o bom estado emocional do paciente aparecem, então, como condições essenciais, não só para a manutenção de seu tratamento, mas também para o prolongamento de sua existência, ampliando as possibilidades de melhora da sua qualidade de vida (Angerami, 2012, p. 148, grifos nossos).

Ao longo do processo dialógico com os pacientes, um deles, o Informante 7, com seus 80 anos de idade, salientou que está em tratamento há cerca de três anos. Quando referidos os seus gostos, ele manteve ênfase ao seu envolvimento com a igreja católica cristã, "Gosto muito de conversar, vou para a capelinha para conversar, faço compras e dirijo. Eu gosto demais de viagens e de hotel fazenda".

O paciente acima demonstrou ao longo de sua fala, que tem uma vida voltada às questões religiosas, canalizando todo o percurso de sua existência, até mesmo antes da descoberta da doença renal crônica, ao divino, na busca de manter sua relação intima com Deus.

O objetivo da religião é a salvação da alma e não a cura, podendo proporcionar, adicionalmente, o bem-estar psicológico, pois o ser humano religioso ancora a sua existência no 'Absoluto'. Pode-se interpretar a religiosidade como um fator de proteção do vazio e do desespero existencial (Frankl, 2003). Nesse sentido, a religiosidade poderia oferecer bem-estar psíquico ao sujeito e ajudar o homem na busca de respostas para suas indagações de cunho filosófico-existencial (Nepomuceno et al., 2014, p. 126, grifos nossos).

O relato de história de vida que o Informante 7 contou foi: "Esse ano farei sessenta anos de casado, bodas de diamante que será transmitido pelo programa da rede vida". Em seu depoimento final ele conclui que "A gente sente bem sendo evangelizado e sendo evangelizador. No início do tratamento eu assustei, fazia tudo errado na alimentação".

Em análise ao fragmento acima podemos destacar que a maneira de enfretamento que o paciente utiliza, se fundamenta em sua fé e na religião que ele possui, quando relata a importância de se ter uma vida pautada nos ensinamentos cristãos.

Durante os relatos foi apresentada a cada paciente a proposta da confecção de um livro da biografia deles, em que seriam colocados os fragmentos de suas histórias de vida, como os que eles mesmos contaram. Todos eles concordaram e demostraram interesse em confeccionar o livro. 


\section{Revisitando e redesenhando a imagem de si através da autobiografia}

$\mathrm{Na}$ segunda parte da realização da pesquisa, a proposta foi que cada paciente confeccionasse, de forma personalizada, a capa do seu livro, utilizando-se da ferramenta da Arteterapia

O principal objetivo desta atividade foi criar um espaço para cultivar possibilidades artísticas, em alguns casos nunca imaginados, tornando palpáveis experiências capazes de permitir transformações positivas aos pacientes, proporcionando momentos de descontração, como foi o caso do Informante 8., portador de deficiência auditiva.

Uma das pacientes, a Informante 9., num contexto anterior havia relatado que quando exercia as funções de professora, possuía habilidades artísticas. Neste dia, ela alegou estar com um comprometimento visual muito grande, e em virtude disso talvez não conseguisse realizar o desenho. O papel do psicólogo nesse momento foi de encorajar, reforçando as qualidades positivas e estimulando que a paciente participasse da atividade.

Entende-se o encorajamento como uma intervenção terapêutica verbal, sob a qual o terapeuta oferece apoio com o objetivo de aumentar a autoestima do paciente, levando o mesmo a acreditar em suas potencialidades e possibilidades. Com isso a paciente aceitou o desafio, e durante a atividade foi possível observar que a paciente apresentava suas habilidades com desenho, e por fim decidiu desenhar e colorir o seu rosto, bem como colaborou com a capa de outros pacientes que solicitaram sua ajuda.

Através dessa iniciativa, essa paciente pôde experienciar momentos de alegria e satisfação notáveis, alegando que há muito tempo não desenhava e por isso pensava que tivesse perdido a habilidade. Essa paciente apresentava uma perda parcial da visão e estava aguardando os óculos ficarem prontos, entretanto, ela concluiu o seu desenho e ainda foi capaz de auxiliar outros pacientes, desenhando o cabelo para uma paciente e o bigode e o óculos de outro.

Outra paciente, Informante 10. que se encontrava em idade mais avançada, escolheu todos os acessórios e caracteres do rosto que representariam a capa do seu livro e não se mostrou muito satisfeita com o resultado final, pois alegou que gostaria que tivesse ficado mais parecido com o rosto dela. No entanto, durante a realização da atividade foi possível estabelecer um diálogo ela, que teve um espaço para contar fatos e angústias do dia a dia, relacionados à sua enfermidade e situações vividas quando ela era mais jovem, o que nitidamente proporciono certo alívio, alegria e descontração.

Nesse momento, o diálogo entre paciente e o pesquisador propiciou a descarga de emoções e sentimentos reprimidos, sob os quais a paciente em questão apresentou-se aliviada após falar. Esse tipo de recurso é conhecido como intervenção terapêutica verbal, e nesse caso, foi denominada de ventilação ou promoção da livre expressão verbal. Com o passar do tempo de atividade com essa paciente, foi sendo construída a importância daquela capa, da forma que ela escolheu, sem se importar com beleza ou perfeição, e sim, com sua singularidade.

Ao produzir uma atividade artística o indivíduo modifica sua realidade desenvolvendo capacidades pessoais e estabelecendo uma comunicação entre o real e o imaginário, transformando assim o ato criativo em expressão pessoal. Dessa forma, o indivíduo constrói sua autonomia e desfrutam do prazer de criar, valorizando suas próprias produções, que foram originalmente criadas e tirando o foco de estereótipos (Loiola \& Andriola, 2011, p. 28).

Em análise ao texto citado acima, bem como considerando o desempenho geral dos pacientes, foi nítida a necessidade das mulheres de se caracterizarem com mais detalhes, bem como o desejo de que os desenhos ficassem belos.

Com o desenrolar da atividade, as mulheres demonstraram mais interesse, participação e se sentiram motivadas, bem como se mostraram satisfeitas ao se depararem com os resultados, bastante originais e peculiares. Já os homens fizeram suas capas com mais simplicidade e rapidez, em virtude de colocarem poucos detalhes. 
Para finalizar a pesquisa na clínica os pesquisadores prepararam uma tarde de música, com a presença de uma colega de turma, com seu violão, e os pacientes puderam escolher o repertório musical apresentado. Durante este momento foi realizado o lançamento do livro e cada paciente recebeu o seu exemplar.

\section{Considerações Finais}

O objetivo pretendido no presente estudo foi alcançado, uma vez que, através do oferecimento de um espaço de escuta proporcionado pelos pesquisadores durante as entrevistas, foi possibilitado aos participantes, que eles contassem suas experiências emocionais e fragmentos de suas histórias de vida frente à DRC, e assim, eles puderam ressignificar suas condições, realizando outras atividades, como a confecção do livro autobiográfico. E assim, atribuir novos sentidos à condição de saúde que eles vivem ressaltando suas potencialidades de criar e produzir, promovendo assim uma melhora na qualidade de vida.

Os resultados identificados no presente estudo constituem um quadro prospectivo que aporta a eficácia de intervenções psicológicas que viabilizem a promoção e saúde e evidenciem as predisposições e habilidades que pessoas com insuficiência renal, diabetes, hepatites entre outras patologias possuem, não se limitando apenas na doença que preexiste, mas buscando meios de ressignificar e pensar sob novos parâmetros e novas perspectivas os conceitos de saúde e doença para a vida esses indivíduos.

Desde o primeiro contato em que os pesquisadores tiveram a oportunidade de estar juntos aos pacientes, foi possível perceber a forma individual que cada paciente dispõe para o enfrentamento da doença e do tratamento, sendo observados de um lado, pacientes que enfrentam a doença de maneira otimista e positiva, outros se fundamentam em suas crenças e na fé, e de outro, aqueles que apresentam dificuldades na aceitação da nova realidade que se apresenta e se sentem desamparados, demandando cuidados psicológicos, reiterando a importância de cuidados relacionados à saúde mental.

Vale destacar que os modos de enfrentamento de aceitação de doença podem ser diversos. Isso reforça que a singularidade nas intervenções e que cada paciente deve ser enxergado em sua subjetividade.

Em suma foi possível observar a importância e relevância que se dá entre familiares e equipe profissional, que acolhem o paciente em tratamento hemodialítico. Ambos os polos, propiciam subsídios necessários para a eficácia do tratamento, além de funcionarem como redes de apoio para o paciente que é assombrado por diversas reações causadas pelos fenômenos psíquicos que a condição que se instaura fomenta em seu modo de existir.

As principais demandas dos pacientes da clínica referida foram de cunho afetivo, pois a reação frente ao diagnóstico da DRC faz emergir sentimentos de medo pelo desconhecimento da doença, incertezas quanto ao futuro e pensar na possibilidade de morte. Outra demanda muito frequente refere-se às limitações impostas pela doença, como as restrições alimentares e hídricas, a falta de lazer, a incapacidade para o trabalho e as doenças que geralmente acometem os pacientes renais crônicos, como depressão, diabetes e deficiência visual.

A rotina e o tempo de permanência na sessão de hemodiálise também apareceram como uma demanda de atenção, visto que submeter-se a uma rotina de hemodiálise em que é necessário frequentar o serviço três vezes por semana, com duração em média de 3 a 4 horas, acarreta para a pessoa um desgaste físico e emocional.

As formas de enfrentamento que influenciam na reação do paciente à doença e no seu estado geral, bem como sua capacidade de compreensão de todo processo de adoecimento puderam ser detectadas no contato direto com os pacientes, o falar das limitações traz muitos sofrimentos, mas o desejo de melhora e o enfrentamento das limitações também ficaram bastante evidentes. 
A realização do presente estudo se mostrou de extrema relevância quando analisada a situação dos pacientes, que frequentam três vezes por semana o atendimento da clínica, para a realização do procedimento de hemodiálise. Tratando-se de um campo fértil para o desenvolvimento de intervenções psicoterapêuticas, pois grande parte desses pacientes apresentaram demandas em que o fazer do psicólogo se apresenta como indispensável, contribuindo para que os modos de vida, posteriores ao descobrimento da doença renal crônica sejam ressignificados de maneira positiva.

Por fim é importante destacar a necessidade que novos estudos, que contemplem os fenômenos psicológicos emergentes frente ao quadro clínico patológico de pacientes que se encontram em tratamento hemodialítico, possam ser realizados, assim como, a aplicação de intervenções psicológicas com o uso da arte terapia em busca do manejo emocional. O presente estudo abre a possibilidade de se pensar em novas estratégias de cuidado social e psicológico para esses pacientes, que em momentos muito particulares de suas vidas, enfrentam o desamparo e a angústia provenientes do processo do adoecer.

\section{Referências}

Ammirati, A. L. (2020). Chronic Kidney Disease. Revista da Associação Médica Brasileira, 66 (1), 03-09. doi:10.1590/1806-9282.66.s1.3.

Angerami, V. A. (org). (2002). Psicologia da Saúde: Um novo significado para a prática clínica. São Paulo: Pioneira.

Angerami, V. A. et al., (2012). Psicossomática e suas Interfaces: O Processo Silencioso do Adoecimento. São Paulo: Cengage Learning.

Botega, N. J. (2017). Prática Psiquiátrica no Hospital Geral. 4. ed. Porto Alegre: Artmed.

Cintra, M. S. \& Bernardo, M. H. (2017). Atuação do Psicólogo na Atenção Básica do SUS e a Psicologia Social. Psicol. cienc. prof., 37 (4), 883-896. doi: $10.1590 / 1982-3703000832017$.

Castellanos, M. \& Pizón, I. (2017). Habilidades para la vida. Espanã. Edex.

Ferrans, C. E., Zerwic, J. J.; Wilbur, J. E., \& Larson, J. L. (2005). Conceptual Model of Health-Related Quality of Life. Journal of Nursing Scholarship,37(4), 336-342. doi:10.1111/j.1547-5069.2005.00058.x

garc, P. P. W. \& Cosmos, M. (2010). Atuação do Psicólogo em Hemodiálise. Rev. SBPH, Rio de Janeiro, (13) 1, $19-32$.

Garcia. T. P. (2004). A contribuição da utilização dos recursos artísticos e lúdicos pelo psicólogo hospitalar no tratamento de pacientes renais no hospital do rim e hipertensão (Trabalho de conclusão de curso (TCC)). Faculdade de Psicologia - Pontifícia Universidade Católica de São Paulo.

Holanda, T. C. M. (2007). Um modelo de intervenção em Psicologia Hospitalar: a psicoterapia breve de apoio. In: Lage, AMV; Monteiro, CKC. (Orgs.). Psicologia Hospitalar: teoria e prática em hospital universitário. 1 ed. Fortaleza: Edições UFC 1, 131-151.

Ju, A.; et al. (2018). Medidas de resultados relatados pelo paciente para fadiga em pacientes em hemodiálise: uma revisão sistemática . American Journal of Kidney Diseases, 71 (3), 327-343. doi: 10.1053/j.ajkd.2017.08.019.

Karimi M. \& Brazier, J. (2016). Saúde, qualidade de vida relacionada à saúde e qualidade de vida: qual é a diferença. PharmacoEconomics, 34 (7), 645-649. doi: 10.1007/s40273-016-0389-9.

Loiola, R. S. \& Andriola, C. J. S. A arteterapia como instrumento do psicólogo na clínica. (2017). Id on Line Rev. Psic. (11) 35 doi: 10.14295/idonline.v11i35.708.

Martínez, V. (2014). Habilidades para la vida. Una propuesta de formacion humana. Colombia: Alternario Educativo.

Marques, E. L. L. \& Delfino, T. E. (2016). Contribuições das técnicas de respiração, relaxamento e mindfulness no manejo do estresse ocupacional. Psicologia.pt, 1-13.

Minayo, M. C. S. (2007). O desafio do conhecimento. Pesquisa qualitativa em saúde. São Paulo: HUCITEC.

Nepomuceno, F. C. L.; Melo Júnior, I. M.; Silva, E. A.; \& Lucena, K. D. T. (2014). Religiosidade e Qualidade de Vida de Pacientes com Insuficiência Renal Crônica em Hemodiálise. Revista Saúde em Debate, (38), 119-128. doi.org/10.5935/0103-104.20140006.

Paula, T. B. et al. (2017). Potencialidade do Lúdico como Promoção de Bem-Estar Psicológico de Pacientes em Hemodiálise. Psicol. cienc. prof., Brasília, (37) 1, 146-158. doi.org/10.1590/1982-3703000682014.

Paiva, F. S \& Rodrigues, M. C. (2008) Habilidades de vida: uma estratégia preventiva ao consumo de substancias psicoativas no contexto educativo. Estudos e pesquisas em Psicologia, (8) 3, 672-684. http://pepsic.bvsalud.org/scielo.php?script=sci_arttext\&pid=S1808-42812008000300009\&lng=pt\&nrm=iso.

Pereira A. S. et al. (2018). Metodologia da pesquisa científica. [e-book]. Santa Maria. Ed. UAB/NTE/UFSM. https://repositorio.ufsm.br/bitstream/handle/1/15824/Lic_Computacao_Metodologia-Pesquisa-Cientifica.pdf?sequence=1.

Picariello, F.; Moss-Morris, R.; Macdougall, I. C.; Chilcot, J. (2016). Medindo a fadiga em pacientes em hemodiálise: a estrutura fatorial do Chalder Fatigue Questionnaire (CFQ). Journal of Psychosomatic Research, (84), 81-83. doi: 10.1016/j.jpsychores.2016.03.12 
Research, Society and Development, v. 10, n. 3, e16210312968, 2021

(CC BY 4.0) | ISSN 2525-3409 | DOI: http://dx.doi.org/10.33448/rsd-v10i3.12968

Reis, A. C. (2014). Arteterapia: a arte como instrumento no trabalho do Psicólogo. Psicologia: Ciência e Profissão, 34 (1), 142-157. doi: 10.1590/S141498932014000100011

Rodrigues, K. A., Silva, E. M. da, \& Barbosa, L. D. da C. e S. (2020). Biopsychosocial repercussions in patients submitted to hemodialytic treatment. Research, Society and Development, 9(7), e814974931. https://doi.org/10.33448/rsd-v9i7.4931

Santos, L. F. et al. (2018). Qualidade de Vida em Transplantados Renais. Psico-USF, (23) 1, 163-172. doi: 10.1590/1413-82712018230114.

Santana, S. S.; Fontenelle, T.; Magalhães, L. M. (2013). Assistência de Enfermagem Prestada aos Pacientes em Tratamento Hemodialítico nas Unidades de Nefrologia. Revista Científica do ITPAC, (6) 3, 1-11. https://assets.unitpac.com.br/arquivos/Revista/63/5.pdf.

Straub, R. O. (2014). Psicologia da Saúde: Uma Abordagem Biopsicossocial. Artmed Editora, 2014.

Silva, A. S.; Silveira, R. S.; Fernandes, G. F. M.; Lunardi, V. L.; Backes, V. M. S. (2011). Percepções e mudanças na qualidade de vida de pacientes submetidos à hemodiálise. Revista Brasileira de Enfermagem, 64 (5), 839-844. doi: 10.1590/S0034-71672011000500006.

Silva, F. S., Caetano, L. A. O., Silveira, C. A. B, \& Junqueira, C. R. A. (2019). A intervenção grupal e o uso da arte como ferramentas produtivas para pessoas com Alzheimer. Vínculo, 16(2), 88-109. https://dx.doi.org/10.32467/issn.19982-1492v16n2p88-109.

Yokota, M. (2004). A experiência de melhora dos sintomas através de arte-terapia em adolescentes com depressão refratária. Tese de Doutorado, Faculdade de Medicina, Universidade de São Paulo, São Paulo. doi:10.11606/T.5.2004.tde-01102014-120213. www.teses.usp.br. 